\title{
Keratocystic Odontogenic Tumor
}

National Cancer Institute

\section{Source}

National Cancer Institute. Keratocystic Odontogenic Tumor. NCI Thesaurus. Code C54302.

An intraosseous odontogenic neoplasm that usually arises from the mandible. It is characterized by the presence of a single or multiple cysts lined with parakeratinized stratified squamous epithelium. The neoplastic lesions may be solitary or multiple. It has the potential for aggressive behavior, local destruction, and recurrence. 